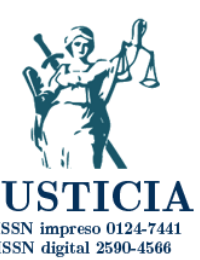

\title{
El papel de la segunda cámara en el entramado jurídico político: Caso Italia
}

\section{The role of the second chamber in the political legal framework: Case of Italy}

\author{
Mijael Altamirano Santiago \\ Instituto Politécnico Nacional, México \\ xhuni@yahoo.es
}

Recibido: 18 de mayo de 2018 / Aceptado: 14 de septiembre de 2018 https://doi.org/10.17081/just.24.35.3395

\section{Resumen}

El presente artículo describe el origen histórico de la segunda cámara en los regímenes representativos y en el contexto de las democracias contemporáneas, con especial énfasis en el caso italiano.

Palabras clave: Segunda Cámara, Sistema Bicameral, Parlamento, Federalismo, Regionalismo.

\begin{abstract}
This article describes the historical origin of the second chamber in representative regimes and in the context of contemporary democracies, with special emphasis on the Italian case.
\end{abstract}

Keywords: Second Chamber, Bicameral System, Parliament, Federalism, Regionalism.

\section{Altamirano Santiago, M. (2019). El papel de la segunda cámara en el entramado jurídico político: Caso} Italia. Justicia, 24(35). 83-103. https://doi.org/10.17081/just.24.35.3395

\footnotetext{
* Mijael Altamirana Santiaga es dactar en ciencia política y saciología por la Universidad Camplutense de Madrid y profesar investigadar del Centro
} de Investigaciones Ecanómicas Administrativas y Saciales en el Instituta Palitécnica Nacional (Méxica), así también es investigadar nacional, nivel I. 


\section{INTRODUCCIÓN.}

El bicameralismo (o la existencia de la segunda cámara) es un tema que ha tenido distintos cauces en los regímenes políticos, sean democráticos o no democráticos, sean federales o no federales. Desde su inclusión en la arquitectura constitucional, el bicameralismo no ha dejado de ser sujeto de reformas y modificaciones constitucionales para ajustarlo al diseño institucional actual.

El sistema bicameral ha sido una materia natural que se asocia invariablemente con el modelo de Estado de tipo federal, no sólo por las colectividades territoriales que se circunscriben en él, sino también por las potestades políticas y administrativas delegadas a las mismas. Cosa contraria experimentan los Estados de carácter unitario y regional, incluso los regímenes políticos de naturaleza monárquica del siglo XIII, al concebir una segunda cámara más por razones políticas que por necesidades propias de la disposición jurídica del Estado.

Este hecho es así en el régimen federal por las provincias, las entidades federativas, los länder, los cantones y/o las colectividades territoriales establecidos en la estructura organizativa del Estado, por el carácter autónomo que gozan en el ámbito nacional- política y administrativamente- $y$, sobre todo, porque históricamente han exigido una cámara de representación territorial en el contexto de los Poderes de la Unión para que las incorpore en la toma de decisiones. En contraste, en los Estados unitarios, regionales o en los regímenes monárquicos, la configuración de una segunda cámara únicamente se explica más por una cuestión ajena al andamiaje constitucional, pues su basamento se ha caracterizado por establecer un sistema de pesos y contrapesos en la dinámica de los poderes para representar a una clase política privilegiada, lo cual termina por debilitar la legitimidad de la segunda cámara o, en su caso, propiciar su desaparición en el arreglo institucional.

Con la referencia de la Cámara de los Lores de finales del siglo XIII y el Senado de los Estados Unidos de Norteamérica de 1787, infinidad de países democráticos y no democráticos han adoptado un sistema bicameral- o una segunda cámara- para completar su esquema institucional, mismo que no es casual, ni mucho menos una espontaneidad o una experimentación al que se recurre para solventar las necesidades inmediatas de la Federación, más bien su configuración y aceptación en la estructura del régimen político representa un requerimiento obligado para los componentes del Estado federalparticularmente el segundo orden de Gobierno- que han exigido ser copartícipes y/o cooperantes en el proceso de decisiones a nivel nacional y, sobre todo, en temas que inciden o lesionan el ámbito de sus respectivas competencias, sean asuntos políticos, administrativos, jurídicos o económicos.

No obstante esta exigencia histórica y la necesidad de adopción de una segunda cámara para fortalecer la presencia de los Estados federados (o las colectividades territoriales) en el seno de los Poderes de la Unión, la representación que ejerce esta instancia cameral ha tenido poco eco y, en consecuencia, su presencia está fuertemente debilitada, incluso, se podría afirmar que es inexistente. En efecto, los constituyentes de la segunda cámara, cuando se abocaron en su diseño y arreglo, se ocuparon de configurar en la mayoría de los regímenes democráticos una cámara política como complemento y apoyo a la primera cámara, mientras que delinearon, en menor medida, el establecimiento de una cámara investida de poder político que ejerciera un sistema de pesos y contrapesos en la realidad nacional y, escasamente, conformaron una cámara de representación territorial que impulsara a las colectividades territoriales o los Estados federados en el contexto nacional.

Teniendo presente estas experiencias y/o antecedentes, muchos teóricos de diferentes latitudes, entre los que destacan Lucas (1996), Manzella (1991), Favoreu (1995), Loewenstein (1983), Guistiniani (1981), Martínez (1994), Tsebelis y Money (1997), Vergotini (1986), Olivetti (1994), González (1984), Lauvaux (1987), Paladin (1984), Pérez (1976), Trivelli (1975), Flauss (1995) y Burdeau (1971) han defendido o, en su caso, han cuestionado la existencia y permanencia de la

Justicia Vol. No. 35: pp. 83-103. Enero-Junio, 2019. DOI: 10.17081/just.24.35.3395 
segunda cámara en la estructura institucional federal, unitaria o regional, pero, sobre todo, en el quehacer político-parlamentario. Las opiniones son diversas y complejas, toda vez que los detractores y los defensores han vertido argumentos de gran valía para la permanencia o no de una segunda cámara, $y$, finalmente, han influido para que algunos estados nacionales la supriman o la adopten.

De ahí, la importancia de este documento para conocer el cauce que ha tenido la segunda cámara en los regímenes políticos y su devenir en el sistema político italiano. Por ello, entonces, se analiza el antecedente histórico del bicameralismo (segunda cámara), su justificación y su presencia en un estado federal y regional, así como también su origen y estatus actual en el caso italiano.

\subsection{Antecedentes históricos del bicameralismo (o segunda cámara)}

Al margen del debate que ha suscitado el origen fundacional del bicameralismo (o segunda cámara) se ha demostrado que históricamente su adopción se configuró sobre una base aristocrática y su existencia respondió a una necesidad real de corregir y servir de contrapeso a la voluntad expresada de su colegisladora, así como al principio de la división de poderes para, de ese modo, moderar la actividad parlamentaria de la primera cámara (Cadoux, 1980).

El rasgo bicameral en los sistemas políticos tiene su origen en dos hechos históricos: la existencia de una monarquía constitucional, como lo señalan González (1984), Finer (1964) y Biscaretti (1987), entre otros, y el establecimiento de la Constitución de los Estados Unidos de Norteamérica de 1787 según Trivelli (1975), García-Pelayo (1984), Sánchez y Mellado (1995), González (1984) y Finer (1964), entre otros.

Con la existencia de una monarquía constitucional, el bicameralismo empezó a tomar forma para expandirse en lo que son hoy los modelos contemporáneos, aunque esta modalidad data de tiempos atrás, más concretamente según González (1984:33) desde la etapa de "la Curia Regis establecido en Inglaterra en el siglo XIV cuyos integrantes eran la clase dominante (grandes barones y los altos prelados)".

En este contexto monárquico constitucional, la presencia de un sistema bicameral fue motivada por dos acontecimientos políticos: i) el surgimiento de un pensamiento liberal conservador que se lanzó en la búsqueda de una institución política análoga a la cámara baja, investida de poder político y administrativo, que operara como un factor moderador y de equilibrio en el seno del Parlamento y ii) la necesidad de acceso de una elite política a la estructura institucional para ser parte del engranaje del proceso decisorio nacional o, más concretamente, el ascenso de nuevas fuerzas políticas a la estructura de Gobierno (Cillán,1990). De esta forma, señala Chueca (1984:63), la concepción liberal buscó "[...] la limitación del poder por el poder como medio de salvaguardar la libertad, no menos amenazada por el tirano que por el Parlamento desprovisto de límites en su actuación".

Este formato bicameral, gestado en ese tiempo, dio vigencia a un Parlamento de carácter dualista cuya naturaleza era imperfecta (o asimétrica), debido a que cada cámara gozaba de una representación y una base competencial diferente, pues la primera cámara estaba basada en la voluntad popular y la segunda carecía de legitimidad democrática, ya que sus miembros eran nombrados por órganos del Gobierno ya constituidos (también conocidos como de segundo grado). Al ser así, señala Negri (1959), en esta cámara sólo tenían presencia los sectores sociales de alta representación, como la nobleza, el clero, la aristocracia y los terratenientes. 
Concebida de este modo, la segunda cámara generó un impacto en el terreno doctrinal, pues se buscó justificar su presencia en el sistema político enfatizando su naturaleza y su función como órgano del Poder Legislativo. Al respecto, Montesquieu (2003), teniendo como base una realidad política caracterizada por la presencia de una monarquía constitucional, hizo una defensa histórica de las segundas cámaras aristocráticas e intentó una justificación teórica al afirmar que en la estructura del Estado existen clases sociales que por su naturaleza deben estar representados en una instancia legislativa para que, de ese modo, se garantice su estatus en el seno de los poderes.

Este perfil aristocrático, del que habló Montesquieu, se consagró en un primer momento en el sistema político británico a través de la asamblea feudal y, posteriormente, en la asamblea de los tres estamentos del reino- los que rezan, los que guerrean y los que trabajan- para finalmente llegar a un Parlamento bicameral, en el cual una primera cámara, llamada de los Comunes, que representaría el tercer estamento o la burguesía, y una segunda cámara, llamada de los Lores, que representaría a los nobles y prelados (Biscaretti,1987 y González,1984). Esta característica, que adquirió el Parlamento británico, resultó inimitable, puesto que estaba vinculada a la evolución histórica de dicho Estado, no obstante, sirvió de referencia para los diferentes regímenes políticos. Esta primera construcción de la segunda cámara transitó entre dos elementos que marcaron su vida hasta bien entrado el presente siglo: primero, su composición basada en una designación hecha por el Rey (es decir, carente de legitimidad democrática) y, segundo, su naturaleza y actuación tuvieron un significado político de perfil conservador que se sustentó en frenar y contrapesar a la cámara baja, cuyo poder estaba por encima de los órganos constituidos.

La posición de Montesquieu generó una serie de reflexiones en pro y en contra como lo recuerda, para el caso español, Cillán (1990:70-71), quien cita los textos de la Asamblea Constituyente Española de 1837, en especial la intervención del diputado González cuando éste afirma:

"Monstequieu dice [...] la nobleza debe ser llamada a componer parte en el Cuerpo Legislativo, porque, en el mismo momento en que sea confundida con los demás ciudadanos, pierde el interés de conservar la libertad, pues entonces las resoluciones serían opuestas a los intereses que debe tener aquélla [...]. Eso es contradictorio. Si Montesquieu hubiera dicho, que, conocidas las circunstancias particulares de Inglaterra, era necesario aceptar ese principio, cabría admitirlo; pero hablar abstractamente y decir ese principio se ha de aplicar enteramente [...] eso es contrariar lo que se supone probar en su célebre obra El Espíritu de las Leyes".

Con independencia de lo anterior, lo cierto es que la segunda cámara, de la que habló Montesquieu (2003), vino a responder a la intención de asegurar la representación de una clase social restringida: la clase distinguida, la cual en una fase del desarrollo político constituyó una fuerza social, económica y política semejante a la fuerza de la mayoría representada en la cámara baja. Su presencia y el matiz que desarrolló en el siglo XIX se caracterizaron por defender la propiedad privada y ejercer la voz de un pensamiento liberal conservador del cual la aristocracia y la nobleza fueron artífices y gestores, como bien lo ilustran los casos siguientes: las cámaras estamentales en Inglaterra, la Cámara de los Pares bajo la restauración en Francia, el Reichsrat austríaco en 1848, el Reichsrat en Alemania durante el II Reich en 1871 y el Senado Italiano del Estatuto Albertino en 1848, entre otros (Jacques y Duby,1997; Biscaretti,1987 y Sagües,1992).

Con la Constitución americana de 1787 se estableció otro tipo de sistema bicameral que respondió a necesidades y realidades distintas a las de la monarquía constitucional (Trivelli, 1975; García-Pelayo, 1984; Sánchez y Mellado, 1995; González, 1984 y Finer, 1964, entre otros). En este caso su base fundacional obedeció directamente a la estructura estatal de tipo federal que adoptó el Estado nacional, lo que, en consecuencia configuró dos niveles de Gobierno: Estado central y estados federados. Para dar cabida a la presencia de los miembros de cada nivel gubernamental en el seno de la Federación y, particularmente, en la legislación federal, la Carta Magna concibió en su marco jurídico la existencia de un Parlamento de carácter dualista. 
La adopción del sistema bicameral en los Estados Unidos de Norteamérica tiene su origen en dos hechos históricos: la mayoría de las colectividades territoriales pertenecientes a la Corona inglesa contaban con un órgano legislativo de tipo bicameral, pero al verse desligadas de ésta, buscaron un formato o una estructura organizativa que le diera viabilidad a su existencia $y$, por consiguiente, pudiera acercarlas entre sí o relacionarlas para defender su independencia.

Cabe señalar también que los estados (ex colonias inglesas) estaban organizados bajo los lineamientos del documento denominado Articles of Confederation de 1777, donde se constataba un modelo estatal de tipo confederado y una organización central en cuyo seno se erigió un Congreso de carácter unitario, en el cual estaban representados los estados de forma paritaria- un voto- y con limitadas potestades por cuanto no podían ejercer atribuciones financieras, presupuestales e impositivas, de modo que todas estas prerrogativas constitucionales quedaban en manos de los órganos de gobierno de los estados (Sánchez,1988). Esta situación, aunada a la ausencia de otros mecanismos o elementos que les diera presencia en el contexto del Estado nacional, llevó a los estados a demandar el establecimiento de un Gobierno eficiente y autónomo que pudiera por sí sólo ser gestor de las decisiones nacionales y que los protegiera de los Estados extranjeros (Dunn y Slann, 1994). Así, los estados pugnaron por modificar los Articles of Confederation y, más concretamente, por construir un nuevo modelo de Estado, el cual fue posible en 1787 cuando los delegados estatales acordaron reunirse en una Convención para hacer las modificaciones pertinentes y reorganizar la situación de los Estados Unidos, dándose ésta por sentada en la Constitución de 1787.

En la Convención de Filadelfia, señala Clinton (1966), todos los estados demandaron un sistema bicameral similar al británico, pero con matices diferentes, dada las condiciones que los envolvían. Así, pues, todos los estados con posiciones diversas plantearon el formato que debía tener el Parlamento. Los densamente poblados demandaron un Congreso en cuya estructura estuvieran representados de forma proporcional de acuerdo a su número de habitantes y los menos poblados defendieron un formato establecido por los Articles of Confederation de 1777, en el cual todos tuvieran una representación paritaria con independencia del tamaño poblacional, económico y territorial.

En el debate surgido a la sombra de esta Convención lo que realmente estuvo en juego fueron dos corrientes que no tenían nada que ver con el carácter ideológico, sino con el carácter político, pues los estados del Norte, que eran y son actualmente industriales, demandaron una representación que garantizara sus intereses frente a los del Gobierno central, mientras los estados del sur, que eran e incluso hoy en día son agricultores, abogaron por un mecanismo de representación que los protegiera para no verse arrastrados por el poderío económico que envolvía a los estados del norte. Una vez superadas las posiciones, se adoptó el Compromiso de Connecticut que promovió un Congreso bicameral basado en un carácter diferenciado a través de una Cámara de Representantes, donde estaban todos los estados representados de manera proporcional, producto de la voluntad ciudadana, y un Senado en cuya sede estaban representados los estados de forma paritaria, sin mediar elección alguna y sin importar la base poblacional, económica o territorial.

De este modo, señala Mény (1990), la monarquía constitucional y la Constitución americana han sido sin duda alguna, desde la perspectiva histórica, determinantes para la adopción de un sistema bicameral, para después ser referentes en la construcción de los diferentes estados nacionales (Fernández, 1982).

Configurado el sistema bicameral en los contextos antes señalados, su evolución ha seguido derroteros distintos. No obstante, según Lalumiére y Demichel (1978), hay que afirmar que su presencia en última instancia se ha debido más a cuestiones políticas que jurídicas, como quedó evidenciado en los anales de la historia y en las normas constitucionales. En efecto, esto es así, ya que la segunda cámara, por un lado, ha representado un cuerpo investido del poder de la otra sociedadde la que habló Montesquieu-, es decir, de la clase distinguida para defender sus intereses frente a la cámara baja, popular y progresista, y, por otro lado, ha integrado a las unidades políticas de una 
Federación cuyo objeto ha sido configurar una instancia que les permita participar en la formación de las decisiones nacionales.

Lo sorprendente en estos dos hechos históricos es que la segunda cámara, aun con su déficit democrático y su naturaleza aristocrática y conservadora, fue gestora de un modelo de equilibrio en el sistema político, pues introdujo elementos de reflexión y de moderación para atemperar o matizar las posibles eventualidades o supuestos radicalismos de su contraparte (Aja y Arbos, 1980), acogiendo a la elite distinguida que estaba fuera de la estructura institucional, como bien lo señala García (1993: 214):

"Durante el Estatuto Albertino la existencia del bicameralismo se justificaba por la teoría política de la monarquía constitucional que encontraba conveniente para el equilibrio del sistema político que la cámara alta, dado su carácter conservador, a causa de su composición, moderara los hipotéticos excesos de la Cámara de Diputados [...]".

Cabe anotar que, a pesar de los elementos (conservador y aristocrático) presentes en la naturaleza de la segunda cámara, el interés que se generó entre progresistas y conservadores por establecer un clima democrático en el Parlamento los llevó a modificar la naturaleza de la segunda cámara. Para cambiar su carácter conservador se introdujeron mecanismos que paliaran esta característica. Como ejemplo de ello, se reorientaron los mecanismos de integración, los cuales no solamente se apoyarían sobre una base electiva, sino también adscriptiva; también cambiaría su representatividad, pues ya no respondería al clero o a los nobles, sino a los estados federados, regiones, provincias o comunidades, o simplemente se guardaría una representatividad política. Respecto a su aire aristocrático, si bien estuvo vigente hasta entrado el presente siglo, hoy en día está ausente en su concepción y su cauce más bien responde a un patrón de checks and balances y de moderación en el entramado institucional (Cillán, 1990).

De este modo, la naturaleza de la segunda cámara a través del tiempo fue- y continúa siendo- una variable que transformó la estructura organizativa del Estado y el significado político en los estados nacionales. Aun así, su desempeño no ha sido, realmente, el de una verdadera cámara que ejerza la condición que por antonomasia le corresponde- un legislador natural- sino más bien ha obrado como una cámara de apoyo técnico, complementaria o, más exactamente, como una cámara de segunda, situación que ha desgastado o ha motivado su cese en algunas constituciones nacionales. En efecto, señala Chueca (1984:65-66):

"La inserción de una segunda cámara en la arquitectura constitucional puede considerarse así como una estructura de apoyo dirigido a limitar y a dividir el poder con arreglo a unos principios básicos contenidos en el ordenamiento constitucional [...]. La segunda cámara es un instrumento dirigido a la consecución de un logro específico, de un objetivo político, mediante la inclusión de una fuerza constitucional que opera en el complejo marco que forma junto con el resto de los vectores del entramado constitucional".

De esta forma, el bicameralismo bifurca la voluntad de las clases sociales al consagrar una representación dual de las fuerzas políticas. En efecto, con él se establece un formato dualista al interior del Parlamento que históricamente llegó a representar una diferencia en la designación de los miembros de la segunda cámara con relación a la primera cámara, ya que la primera estuvo compuesta por legisladores elegidos a través de la voluntad popular manifestada de manera directa y la segunda se fundó bajo una técnica menos democrática, pues su integración se basó en un sufragio censitario, sufragio indirecto, o bien de segundo o tercer grado (Wheare,1981).

Lo que actualmente se puede percibir es que el progresivo nivel de democratización que se está dando en el seno de los estados nacionales, iniciado desde principios del siglo pasado, y que se refleja en la adopción del sufragio universal directo, ha puesto en entredicho al bicameralismo y, en consecuencia, lo mantiene en dos escenarios: o bien se contrapone al proceso democrático surgido en 
los diferentes estados nacionales o, tiende a ceder ante la presión democratizadora, perdiendo su origen y significado fundacional (Weber,1972).

La democratización de las instituciones de representación en los diferentes sistemas políticos ha llevado por diversos derroteros la permanencia del bicameralismo transformando su rasgo fundacional y su concepción liberal-conservadora, o simplemente ha propiciado su cese en la arquitectura institucional. Los que transformaron su base estaban conscientes que debían cuidar la modalidad de su elección, su representación y su base competencial para evitar en todo sentido que ambas cámaras fueran simétricas. Este hecho condujo a que, en la mayoría de los países, la segunda cámara tuviera una mínima presencia en el quehacer nacional o, en su caso, se abocara a cuestiones específicas.

I.1. La justificación jurídica-política del bicameralismo (o segunda cámara)

El mantenimiento de un Poder Legislativo de carácter dualista en los estados nacionales ha motivado que se generen infinidad de voces sobre su existencia y permanencia. En efecto, al repasar la literatura que da cuenta sobre el bicameralismo, se constata que existe un amplio sector que defiende y justifica su valía en los estados nacionales, mientras que otro segmento, también extenso, lo juzga como un elemento negativo y entorpecedor de la dinámica político-parlamentaria.

Lucas (1996), Manzella (1991), Favores (1995), Loewenstein (1983), Guistiniani (1981), Tsebelis y Money (1997), Vergotini (1986), Olivetti (1994), González (1984), Lauvaux (1987), Paladin (1984), Pérez (1976), Flauss (1995) y Burdeau (1971) han señalado múltiples argumentos a favor del bicameralismo, algunos de ellos son:

a) que su presencia es imprescindible de modo relevante en un Estado federal, ya que existen el pueblo en su totalidad, por un lado, y las unidades políticas federadas, por otro, y con él se da vida a la representación de ambos niveles de Gobierno, Federación y Estado federado; b) que su existencia constituye un elemento que permite el equilibrio en la organización del Estado al evitar que la cámara baja, producto de la voluntad ciudadana, sea la única en la formulación y elaboración de las leyes; c) que su constitución representa el equilibrio del organismo legislativo, el cual, al dividirse, limita y atempera el dinamismo de la cámara baja; d) que su existencia permite reflejar la estructura social en su conjunto, dado que ambas cámaras responden a elementos distintos; e) que las dos cámaras ofrecen mayor legitimidad y madurez en la deliberación debido a que, al intervenir ambas en el contexto de una iniciativa legislativa, se facilita la adopción de decisiones más correctas o acertadas; f) que su presencia es necesaria cuando se trata de valorar las autonomías territoriales, pues, mientras la primera cámara representa al pueblo en su conjunto y constituye un elemento de garantía de la unidad nacional, la segunda cámara trae consigo el reconocimiento de la garantía de las entidades territoriales menores y permite su participación en la construcción de la voluntad nacional; g) que se vuelve deseable su presencia, pues se demanda una cámara que imponga un equilibrio e impida el predominio de una sola cámara, el cual puede conducir fácilmente al despotismo de la mayoría; h) que su presencia da prudencia y mejora la calidad en la formación de las leyes, dado que existen dos órganos legislativos que las elaboran y analizan; i) que su existencia trae consigo madurez en la legislación y evita que intereses particulares se impongan en los trabajos camarales; j) que su presencia modera el poder, etcétera.

Los detractores del sistema bicameral, entre los que destacan Martínez (1994), Trivelli (1975), Jacques y Duby (1997) y Pasquino (1977), tienen argumentos sólidos que giran sobre tres líneas: a) el hecho de que ambas cámaras tengan los mismos poderes y la misma representación trae consigo una duplicidad de órganos que invalida la existencia de alguna de ellas; b) la existencia de un Poder Legislativo de carácter dualista hace más lenta la producción de las leyes e, incluso, puede llegar a 
ocasionar una parálisis en el seno de los poderes del Estado nacional y c) el bicameralismo es un factor que complica la vida política y la estabilidad nacional, pues es latente en la formulación de las leyes, al pasar por dos órganos legislativos, la posibilidad de un desacuerdo camaral.

El debate que ha surgido en torno a la presencia o ausencia del bicameralismo ha estado acompañado por una infinidad de elementos, especialmente por el avance democrático y la configuración de un sistema de pesos y contrapesos en el régimen político que permita la vigencia de la división de poderes. No obstante, este principio democrático, al que siempre se apela en los argumentos, ha tomado diferentes cauces en el momento mismo de discernir sobre el bicameralismo: i) que se prescinda de la existencia de un sistema bicameral (los casos de Suecia y Dinamarca), ii) que se fortalezca para garantizar el buen gobierno de los poderes públicos (el caso estadounidense) y iii) que represente a las unidades territoriales en una Federación (los casos de Alemania y Austria).

\section{I.2. La presencia del bicameralismo (o segunda cámara) en un Estado} de tipo federal

Es bien sabido que el bicameralismo no es una categoría monolítica, ni homogénea, puesto que la dinámica que ha adquirido en los distintos regímenes políticos lo ha llevado a erigirse en la realidad jurídica y política en un verdadero órgano, con potestades constitucionales y de representación, capaz de ejercer un sistema de pesos y contrapesos en el entramado institucional.

La experiencia histórica de los países que se circunscriben dentro del proceso de federalización ha conducido a que la existencia de este modelo provenga de vertientes diferentes, como bien lo señalan Hesse y Wright (1996:3):

“[...] ser un resultado consciente y deliberado rechazo a la opresión del centro bajo un régimen autoritario, ser un intento de ajuste institucional proveniente de una división cultural, o ser un compromiso en reacción al incremento al déficit de cumplimiento del Estado central en un esquema tradicionalmente unitario".

La esencia de un modelo federal responde a que en él subsistan la participación y representación de los estados miembros (colectividad o unidades territoriales) en el proceso de decisiones en el ámbito federal, lo que conlleva a la adopción de un sistema bicameral. De aquí la validez de la afirmación de Duverger (1961:32), cuando dice que "[...] en el interior de un régimen democrático, el bicameralismo no se justifica verdaderamente, más que en el cuadro de un sistema federal". Este señalamiento es válido si se tiene en cuenta que de 21 países de carácter federal sólo 4 de ellos adopta un sistema unicameral, en tanto que el resto, 17 , se inclinan por un régimen bicameral. Como lo señala Croisat (1994:32):

"Las unidades federadas deben estar representadas y participar en las decisiones federales (por lo que tal principio de participación) [...] se ejerce en el marco del bicameralismo federal, donde la segunda cámara representa, de forma más o menos igualitaria, a todos los componentes federados en la sede de la Federación".

La representación de las unidades políticas en el centro nacional viene siendo un objetivo prioritario que tiene todo Estado federal. Por esta razón, en la organización de las instituciones políticas en una estructura federal, además de un órgano jurisdiccional para solucionar los conflictos inter o intraestatales, la adopción de un sistema bicameral, en especial la segunda cámara, permite cumplir dos funciones relevantes en la construcción del Estado: establece el equilibrio entre las unidades políticas que integran el Estado, dándoles voz y presencia al incorporarlas en las decisiones federales, 
y constituye un sistema de pesos y contrapesos entre las estructuras que componen el régimen político y en el contexto del Poder Legislativo. Sobre este tema, señala González (1984:36-37):

“[...] La reconocida necesidad de una segunda cámara en los estados federales se concretaba en dos exigencias distintas: que todos los estados miembros tuvieran igual representación en la segunda cámara, con independencia del tamaño e importancia, y que el poder de la segunda cámara fuera sensiblemente igual a la cámara de representantes del pueblo".

De esta manera, como lo expresa Lucas (1996), el formato bicameral es más propio en un modelo de Estado federal, puesto que en él se concibe la existencia de dos niveles de Gobierno y un Parlamento, bajo esta característica, da cabida a ambas representaciones: al pueblo en su conjunto y a las unidades políticas federadas. En este mismo sentido, señalan Tsebelis y Money (1997), este modelo de Estado representa para el sistema bicameral un espacio donde su legitimación es incuestionable- en la mayoría de los casos- y sus poderes son francos.

De igual modo, estos mismos autores aseguran que en un modelo federal la función de la segunda cámara, además de ser un órgano territorial, es impedir que los estados federados poderosos (política y económicamente) absorban a sus similares; de igual forma este modelo imposibilita que los estados federados sean absorbidos por las decisiones y la estructura de la Federación.

De ahí que la existencia de un sistema bicameral en un Estado federal es una indicación de que los valores implícitos en el federalismo son omnipresentes en el sistema político y, en consecuencia, la segunda cámara se constituye en un aliado del federalismo en el sentido de que la interacción de la Federación y los estados federados, regiones, provincias o comunidades sólo es viable mediante la adopción de un Parlamento con esta característica y en el cual cada uno de los órganos aglutine por separado a los dos niveles del Gobierno para que sean copartícipes en la formulación de las legislaciones federales y en la toma de decisiones nacionales.

Con ello, el bicameralismo no sólo permite la coordinación de las colectividades federadas (o unidades territoriales) en la estructura estatal mediante la representación, sino también las convierte de facto en defensoras de sus propios intereses a nivel federal.

En suma y con base en lo señalado por Loewenstein (1983:356 y 358), se puede afirmar que:

“[...] la organización federal se basa en la idea de que la Constitución Federal establece un compromiso entre los intereses de la unidad nacional y de la autonomía regional [...]. El principio de distribución del poder estatal entre el Estado central y los estados miembros está anclado en las disposiciones constitucionales sobre la formación de la voluntad estatal de la Federación. El lugar tradicional para la participación de los estados miembros en la decisión política fundamental y en la ejecución de la decisión es la segunda cámara [...]".

Sobre esta misma tesitura se expresa Mouskheli (1931:178):

“[...] el Estado federal [...] contiene un doble elemento que no se encuentra en un Estado unitario: el pueblo tomado como una masa total, y el pueblo dividido en estados particulares. En consecuencia, es indispensable asegurar a cada uno de estos dos elementos una representación aparte, lo que constituye uno de los rasgos más expresivos del régimen federal".

I.3. La presencia del bicameralismo (o segunda cámara) en un Estado de tipo regional

Antes de definir las características y las condiciones que envuelven a un Estado de tipo regional, es pertinente dar cuenta del perfil que guarda un Estado de carácter unitario, puesto que éste permitirá

Justicia Vol. No. 35: pp. 83-103. Enero-Junio, 2019. DOI: 10.17081/just.24.35.3395 
entender con más rigor lo que es realmente el modelo regional. De acuerdo a Ferrando, citando a Prélot (1978), la denominación de Estado unitario se justifica porque esta forma política del Estado es uno en su estructura, en su elemento humano y en sus límites territoriales. Así, el Estado unitario como organización política es único porque consta de un solo aparato gubernamental, que lleva a cabo todas las funciones estatales y de un ordenamiento constitucional único. Asimismo, su organización política abarca una colectividad unificada considerada globalmente, sin tomar en consideración las diferencias individuales o corporativas, y las decisiones de los gobernantes obligan a todos los nacionales de modo igual (homogeneidad del poder). Incluso cubre todo el territorio estatal de modo idéntico, sin conocer diferencias entre las distintas entidades locales.

Por consiguiente, la presencia de un modelo bicameral en un modelo de Estado de tipo unitario es poco común, dadas las condiciones que envuelven al Estado y el limitado margen de acción o poder que tienen las colectividades territoriales en la sede nacional. Tanto es así que los anuarios y documentos del Centro Internacional de la Unión Interparlamentaria (1986) señalan que, de 129 estados unitarios, sólo 38 de ellos establecen un sistema bicameral y los restantes 91 se inclinan por un sistema unicameral.

De constituirse un modelo bicameral en un Estado de carácter unitario, señala Trivelli (1975), la superioridad de alguna de las cámaras siempre se impone, en especial en el ámbito presupuestal o financiero, y la razón histórica de su adopción en dicho contexto es la defensa de los intereses de las clases sociales superiores- aristócratas, alta burguesía, etcétera- motivada más por la inercia históricopolítica que por la realidad existente. Por su parte, Cillán, citando a Laférriere (1990), señala que la existencia de una institución dualista en un Estado unitario está motivada, especialmente, por el deseo de contrapesar, o al menos de moderar la influencia de algunas de las asambleas.

Dentro de esta categoría de estados unitarios subsisten modalidades que bien pueden ser centralizadas, descentralizadas o regionales (Ferrando, 1978). En el primer Estado, denominado Estado unitario centralizado, las unidades políticas no tienen la potestad de auto-gobernarse (políticalegislativa), ni de instrumentar Constitución política alguna, quedando para ellas la prerrogativa administrativa que el propio Estado nacional les delega. La capacidad de los entes territoriales es limitada, puesto que la hegemonía del poder político es ejercida por el Estado central y su concurrencia en la formación de la voluntad nacional es nula al estar imposibilitados para tener presencia o representación en los órganos legislativos nacionales por las características propias del Estado. De este modo, las colectividades territoriales conforman un todo con el Estado central. En el segundo Estado, denominado Estado unitario descentralizado o regional, el Estado está alejado de la dinámica que impone un Estado unitario centralizado y próximo a un Estado federal, puesto que la estructura institucional que diseña es similar a este último y porque configura dos niveles de Gobierno (Estado central y comunidades o regiones).

De esta manera, la naturaleza del Estado unitario descentralizado o regional conduce a que las colectividades territoriales tengan un cuadro de instituciones con capacidad administrativa y/o política de autogobierno, aunque estén imposibilitadas para configurar un poder constituyente. Holanda y Francia son ejemplos de Estados unitarios descentralizados (Roja, 1991 y Delcamp, 1994) donde las unidades territoriales- llámese provincias, departamentos o regiones- solamente tienen la potestad de auto-gobernarse administrativamente, mas no políticamente.

Lo anterior conduce a que dichas colectividades estén sujetas a las decisiones emanadas del Gobierno central y a que la presencia de las mismas (es decir, de las colectividades territoriales) en la sede nacional sea nula, dado que la segunda cámara no se erige como un órgano de representación territorial, sino como una institución eminentemente política, similar a la cámara baja. Esta dinámica creada en el Estado unitario descentralizado es así, pues solamente existe el reconocimiento de las colectividades territoriales en el contexto nacional. 
El Estado regional, por su parte, permite a las colectividades territoriales tener una capacidad de autogobierno política y administrativa y estar representadas en la sede nacional a través de la segunda cámara, esto se parece a la realidad que plantea la dinámica creada en un Estado unitario descentralizado (Petschen, 1993). La diferencia que existe entre un Estado unitario descentralizado y un Estado regional, como lo señala Ferrando (1978), es que en el primero sólo existe una descentralización administrativa, hecho que limita la autonomía de los entes territoriales en la dinámica nacional, en tanto que en el segundo existe una descentralización política y administrativa, lo que conduce a que las colectividades territoriales tengan instituciones investidas de poder para normar la vida de la propia región, aunque muy limitadamente.

El Estado regional, señala La Pérgola (1979:170):

“[...] tiene una estructura análoga a la del Estado federal, aunque no idéntica, en la medida en que puede adoptar determinados elementos de este último y rechazar otros tal como ha sucedido en Italia, donde [...] la Constitución y la Corte Constitucional cumplen funciones similares a las que realizan respecto de los Estados-miembros dentro de un Estado federal, en tanto que no se ha adoptado un dispositivo de participación de las Regiones análogo al representado por las segundas cámaras federales".

La estructura institucional y las características que tiene un Estado regional guardan cierta similitud y pocas diferencias con respecto al Estado federal, como bien lo anotó La Pérgola en el epígrafe anterior, en varios sentidos:

a) existen dos niveles de Gobierno (Estado central y regiones o comunidades); b) se establece una distribución de competencias en los dos niveles de Gobierno, lo que hace que los entes territoriales tengan facultades y capacidad legislativa en su ámbito territorial; c) se configura un Tribunal Jurisdiccional para dirimir los conflictos de competencia; d) las regiones gozan de la facultad de tener un Poder Legislativo, Ejecutivo y Judicial; e) las regiones, para normar la vida política y administrativa de su ámbito territorial, tienen un Estatuto de Autonomía, que es distinto a la Constitución que tienen los estados federados; f) las regiones no gozan de un poder constituyente, sino que éste queda en el ámbito competencial del Estado central; por el contrario en un Estado federal existe una pluralidad de poderes constituyentes; g) las regiones tienen una nula presencia en las reformas constitucionales, a diferencia de la fuerte presencia de los estados federados en lo que a reforma constitucional se refiere y h) la presencia de una segunda cámara que se estructura sobre una base territorial.

Si bien es cierto que en la estructura institucional de los dos modelos de Estados (regional y federal) se configura una segunda cámara, la dinámica y la representación que de ella emanan se diferencian en gran medida a pesar de que en los dos contextos se constituyen sobre una base territorial. Tal diferencia se debe básicamente a la naturaleza de cada Estado, es decir, mientras en el Estado federal existe un pacto entre los estados federados, en el Estado regional solamente existe el reconocimiento de las colectividades territoriales en la dinámica estatal. El pacto que se establece en el Estado federal obliga a que las colectividades federadas estén representadas en la formación de la voluntad nacional y, en consecuencia, la segunda cámara debe ser una expresión de los intereses territoriales. Por su parte, el reconocimiento que existe en el Estado regional impide que las unidades territoriales tengan representación o presencia alguna en el contexto nacional, lo que conduce a que la segunda cámara sólo sea considerada en el plano jurídico como un órgano territorial. No obstante la segunda cámara, así no responda y no coincida con la naturaleza impuesta en el modelo federal, viene sólo a integrar (no a representar) a las colectividades territoriales en la sede del Estado nacional, con el fin de evitar que existan brotes separatistas, se erige como un órgano que permite el perfeccionamiento de la legislación nacional y equilibra la dinámica parlamentaria (Tsebelis y Money, 1997).

En suma, como bien lo señalan los apologistas del bicameralismo, la presencia de este sistema bicameral en los Estados unitarios centralizados, descentralizados o, en su caso, regionales sólo ha respondido a dos elementos: i) permite un examen más profundo y mesurado de los procesos 
legislativos y ii) funciona como una fuerza estratégica que contrarresta y modera el poder en el seno del Estado, particularmente en el Parlamento.

I.4. Origen, cauce y estado actual del bicameralismo (o segunda cámara) en el caso Italiano. Una visión jurídica-política

El Senado actual señalan Grangé (1995) y Rescigno (1995), le precede el Senado del Reino de Italia adoptado dentro del sistema bicameral de 1848. En efecto, la existencia de una monarquía constitucional de carácter dualista, condujo a concebir un Parlamento bicameral, con el objeto de que la segunda cámara, representara los intereses de la monarquía y, al mismo tiempo, se erigiera como una institución de poder. De ahí que se adopta el Senado en el sistema político dando vida a una cámara clasista.

La tradición bicameral en Italia se inicia con la Constitución Napolitana de 1799, cuya fuente inmediata fue el modelo francés, que en ese entonces dominaba al Estado italiano. Tal sistema configuró dos cámaras con poderes desiguales, no sólo en su composición, sino también en cuanto a la base competencial que ambas ejercían en el entramado nacional. La primera cámara representó a la base social y la segunda cámara a las clases distinguidas. Si bien es cierto que a las dos les correspondía el quehacer legislativo, la cámara baja le fue atribuida la facultad de aprobar todas las leyes provenientes de su colegisladora, y la cámara alta le fue otorgada la potestad de iniciativa legislativa. Esta situación provocó que ambas fueran diferenciadas (o asimétricas) en el ejercicio de sus funciones como lo afirman Aimo (1977) y Ghisalberti (1978).

A partir de esta etapa la vida italiana transitó por momentos diferentes. Una vez concluida la guerra contra el régimen austríaco y derrotado éste, las diferentes regiones se aventuraron a debatir el 7 de febrero de 1848 en el seno del Consejo de Conferencia para preparar una Carta Constitucional que rigiera en la dinámica nacional, acogiéndose éstas finalmente por el Estatuto Albertino- que el Rey de Cerdeña, Carlos Alberto estableció para su Reino, como Constitución del Reino de Italia- (Ferrando, 1978).

Consecuencia del proceso jurídico-político impuesto por el Estatuto Albertino, se introducen cambios en la sede parlamentaria que facilitó el trance a un nuevo modelo de gobierno denominado monárquico-parlamentario (Ghisalbert, 1974). Con este hecho la monarquía siguió vigente en el sistema político italiano, aunque con una mínima participación en el entramado legislativo (Allegretti, 1989).

De este modo, el Estatuto Albertino constituyó una monarquía, que estaba representado sobre un Consejo de Estado y un Rey, mismos que ejercieron la dirección política y administrativa del Estado, y un Poder Legislativo de perfil bicameral imperfecta, en donde ambas cámaras se diferenciaban, tanto en los sistemas de representación, como en las competencias. La cámara baja tenía una base electiva y popular, lo que traía consigo que ésta fuera un órgano constituido con una legitimidad democrática limitada; en tanto el Senado respondía a un carácter regio y no electivo puesto que se integró en su mayoría por personas pertenecientes al clero, a hacendados, a la familia real, entre otros. Todos designados por el Rey bajo una modalidad vitalicia (Sagües, 1992). En cuanto a la base competencial, el Senado operó conjuntamente con su colegisladora en el quehacer legislativo, aunque con poderes limitados. En atención a esta configuración, el Senado funcionó como un instrumento político de la Corona y, en consecuencia, representó para el Reino de Italia, una fuerza y un mecanismo que balanceó los poderes frente la potestad constitucional y política que reunía la cámara baja (Aimo, 1977).

La dinámica política surgido del Estatuto Albertino, no sufrió altibajos durante varios lustros, sino hasta 1923 cuando se establece el régimen fascista, mismo que condujo a reestructurar la posición 
de las instituciones políticas, así como también de las colectividades territoriales del Estado hacia un modelo de Estado centralista, provocando, entre otras cuestiones, la ruptura con el Estatuto Albertino concebido en 1848. Dicha situación, señala Grangé (1995) propició la subordinación de todo el aparato institucional (Gobierno y Parlamento) y los diferentes entes territoriales existentes al Poder Central.

Tras la segunda Guerra Mundial y paralelo a la elección de la Asamblea Constituyente, el 2 de julio de 1946 se sometió a un referéndum popular lo relativo al formato de gobierno que debía adoptar Italia, el cual propició que se adoptara una forma republicana, dejando atrás el formato impuesto por la monarquía constitucional. En la Asamblea Constituyente, señalan Cheli (1978) y Biscaretti (1987) se generó un álgido debate sobre la viabilidad de contar con un sistema bicameral y las características (o formato) que debía tener. En el desarrollo del debate surgieron tres posiciones claramente definidas según Lodici (1999): i) La ejercida por el PCl que demandó la adopción de un modelo monocameral o, en su caso, la constitución de un modelo bicameral diferenciado en el cual la primera cámara tuviera la supremacía del poder político y la segunda cámara un papel marginal; ii) La sostenida por el PDC (Conti y Ambrossini), que sugirió un Senado elegido por las regiones, sindicatos y universidades, y un número reducido de sus miembros fuera nombrado por el Jefe de Estado; y iii) La presentada por el PRI y un sector del PSI, que demandaron un Senado legitimado por el voto popular y donde la población estuviera representado. El argumento que más pesó para los Constituyentes, fue la experiencia impuesta en el período del Reino de Italia en el sentido de que el Senado no sólo constituyó un instrumento que perfeccionó la labor legislativa, sino que también, fungió como un garante contra los abusos y las acciones mal intencionadas de la Cámara baja, incluso se resaltó el papel de equilibrio que ejerció en el práctica política (Spaldoni, 1993).

Con base a estos argumentos, finalmente se adoptó un bicameralismo puro (Paladin, 1984) en donde ambas cámaras se configuran en igualdad de condiciones para ejercer las potestades constitucionales, del mismo modo, se les dotó de un sistema electoral diferenciado. Así, pues, se establece en Italia una nueva etapa constitucional y un nuevo régimen político-administrativo basado en un formato parlamentario en el cual se reconocía la presencia de un cuadro de instituciones políticas (Chimenti, 1992); es decir, un Poder Ejecutivo, un Parlamento bicameral y una Corte Constitucional; así como también la adopción de un modelo de estado tipo regional y, en consecuencia, un numeral de colectividades territoriales, llámese regiones, provincias y municipios.

Este formato adoptado en la Constitución de 1947- hoy operante- señala Pérez (1997), posee dos características que habría que resaltar: a) la República está protegido por un precepto constitucional que impide su revisión o modificación y b) las instituciones políticas, contrario a la República, están sujetos de un precepto más flexible dado que existen procedimientos o mecanismos constitucionales para propiciar su revisión en el entramado jurídico-político. Asimismo, expone Rodríguez-Aguilera (1988) hay que destacar el papel asignado a la ciudadanía de incidir de manera activa y, en su caso, corregir las legislaciones originadas en las cámaras vía la aplicación de un referéndum abrogativo.

La Asamblea Constituyente al integrar este concepto- el referéndum abrogartivo, este casoal marco constitucional italiano lo concibió como un instrumento de corrección del electorado respecto de la producción legislativa de la mayoría parlamentaria o, mejor dicho, según Crisatulli y Paladin (1990) viene a representar un garante o defensa de la sociedad civil frente a determinadas actitudes del poder político de las cámaras.

Con la reinstalación del Senado por los constituyentes de 1947 en la dinámica política italiana, éste no ha sido objeto de una revisión constitucional plena que implique un cambio en su formato, más bien han habido reformas parciales que han llevado a modificar su sistema electoral, sin que ésta afectase de manera significativa su posición frente a los otros poderes que integran el marco constitucional-institucional. En efecto tales reformas habidas, sólo se han abocado en darle nuevos matices en cuanto a su sistema de representación, toda vez que alteró el número total de sus 
miembros, el mandato legislativo de sus miembros, el sistema de elección, etcétera, pero ninguna de ellas hasta ahora ha tendido a transformar el formato bicameral en el cual se asientan las cámaras.

Desde 1947, las reformas al Senado han sido distintas en el tiempo. La primera reforma constitucional de 1963 modificó el número total de los miembros de las cámaras y la modalidad de la elección de las mismas. De ahí, el Senado se integró de un total de 315 miembros, todos elegidos mediante el principio de representación proporcional con un mandato legislativo de 5 años. En 1971, se modificó parcialmente el reglamento parlamentario para que las fuerzas políticas minoritarias pudieran asumir un papel en el indirizzo político (Luciani, 1993).

Ya en la década de los noventa, llegan otras dos reformas señalan Presno (1994) y Pappalardo (1995): La primera en 1991 relacionada con la institución presidencial y la segunda en 1993 relativo al sistema electoral de los órganos legislativos. La primera se encaminó a darle una nueva vertiente a las facultades del Presidente de la República, puesto que se le otorgó una ampliación de sus poderes, que le permiten proceder a la disolución de las cámaras o, una de ellas, en el supuesto caso de que los seis meses del mandato presidencial coincidan con los últimos seis meses de la Legislatura- artículo $88.2 \mathrm{Cl}$-. La segunda introdujo una modificación al estatus de los miembros de las cámaras y al sistema electoral de las mismas.

Sobre esta reforma de 1993, señalan Pérez (1997) y el mismo Pappalardo (1995) tuvo su razón de ser a varias cuestiones: a) la existencia de una elevada fragmentación al interior de las cámaras que impedía cualquier consenso parlamentario ; es decir, existían en la Cámara de Diputados 16 grupos, de las cuales 6 de ellas tenían el $2 \%$ de la votación nacional; en tanto en el Senado, había 18 , de los cuales 8 tenían menos del 1\%; b) el repudio al PDC como gobierno de partido; c) el surgimiento de nuevas fuerzas políticas ( $\mathrm{LN}$ y FI); d) el crecimiento de los actos de corrupción; y e) un alto desprecio por la clase política gobernante. Incluso resalta Pérez, que si bien todos estos factores incidieron para concretar esta modificación constitucional, fue la ciudadanía la que propició este reforma vía referéndum popular.

En efecto, el movimiento refrendario (referéndum abrogativo) promovido por la sociedad italiana harto por los excesos cometidos por los partidos políticos y la clase política gobernante obligó a las cámaras legislativas a derogar algunas disposiciones relativas a la cuestión electoral del Senado y transformar la demanda social en ley, dando vida a la reforma constitucional de 1993 como lo describe este mismo Pérez (1997).

Por toda esta modificación introducida por la reforma de 1993, la actual composición del Senado tenga como base el concepto regional en donde todos sus miembros son elegidos de manera directa (315), previniendo que ninguna de las regiones tengan menos de 7 senadores, con excepción de 2 regiones: Molise y Valle de Aosta, que tienen 2 y 1, respectivamente. Al tiempo también se establece una distribución de escaños entre las regiones en función a los últimos datos que arroje el censo de población-artículo $57 \mathrm{Cl}$.

El Senado, además de contar con este primer grupo de senadores elegidos directamente por la voluntad ciudadana, integra otra categoría de senadores que es nombrada por el Presidente de la República y no podrá ser mayor de cinco. Este grupo tiene poca relevancia ya que carece de legitimidad democrática y no goza de una presencia decisiva en la integración o formación de grupos que incidan en la actividad parlamentaria puesto que representa el $4.3 \%$ del total de miembros de esta cámara. Estos nombramientos señalan Rubio y Daranas (1997: 350):

“[...] se trata en realidad de una potestad más bien del Gobierno que del Presidente, toda vez que, según el artículo 89, ningún acto del Presidente de la República será válido si no va refrendado por uno de los ministros como mínimo [...]".

Lo que viene a significar que, el papel del Presidente de la República en este acto sea marginal, a pesar de que el mandato constitucional le atribuye esta prerrogativa. 
Sobre el sistema electoral anota Uriarte (1994:280):

"[...] no introduce un sistema mayoritario puro ni corregido, sino un mixto, que es de mayoría en sus tres cuartas partes y proporcional en una cuarta parte, por lo que no falta quién lo considera un sistema esquizofrénico, por inspirarse en dos lógicas opuestas".

En este mismo sentido se expresa Chalvidan (1990) cuando habla del sistema electoral vigente en el Estado italiano.

También hay que resaltar que esta reforma introdujo que la modalidad para la asignación de los escaños fuera más flexible dado que sólo se exige al candidato al Senado que logre juntar en su haber un mayor número de votos válido en el Colegio electoral, sin que tenga que superar una barrera impuesta por la legislación- que era de $65 \%$ hasta antes de 1993-. Es decir, los escaños que son distribuidos vía sistema proporcional se reparten actualmente teniendo como base los votos emitidos en la Región a cada partido político entre el total de votos obtenidos en dicha Región, al que se le aplica la fórmula de $D^{\prime} H o n d t$. Con este hecho se adopta una mayoría simple frente a la mayoría absoluta que rigió en la dinámica electoral italiano de antaño. Asimismo, se evita el alto grado de fragmentación en el espectro político, se incrementa la responsabilidad entre representantes y representados, y se facilita la conjunción de acuerdos entre los partidos políticos para la formación de gobierno.

Por otro lado, hay que hacer hincapié que originalmente la norma constitucional de 1947, estableció que el mandato senatorial fuera de 6 años, pero debido al incidente que provocó la disolución anticipada de la misma, no fue posible aplicar esta modalidad. Ante esto, llegó otra Ley Constitucional, del 9 de febrero de 1963, que lo modificó y fijó un mandato para ambas cámaras de 5 años, salvo para aquellos senadores designados por el presidente de la República que son de carácter vitalicio, ambos actualmente operantes- artículo 59 y $60 \mathrm{Cl}$.

Las reformas constitucionales impulsadas en los 80-90 y otras que están por configurarse e implantarse desde el plano institucional en el sistema político italiano, han sido ya estudiadas y valoradas en el seno de una Comisión bicameral como lo afirma Luciani (1993). La necesidad de replantear el marco constitucional e institucional del Estado es un fenómeno que se viene arrastrando desde 1980 con la creación de una comisión bicameral (llamada Comisione Bozzi, en honor al presidente que la dirigió en su momento) y, posteriormente, con la Comissione Bicamerale (Paladín, 1998; Herrando, 1998).

Sobre los trabajos de la Comissione Bozzi, escribe Aragón (1990:140) dio como resultado

“ [un] informe en el cual se aboga por dotar a la Cámara de Diputados de prevalencia en el ejercicio de la función legislativa y al Senado de prevalencia en el ejercicio de la función de control (bicameralismo diferenciado) haciendo, pues, de aquella Cámara, la legisladora ordinaria y conservando algunas categorías de leyes como bicamerales [...]".

De ahí, que esta comisión diseñó un cuadro de competencias diferenciadas para ambas cámaras con el objeto de evitar la duplicidad de funciones, ya que este factor ha significado en gran medida la debilidad de la institución parlamentaria.

A pesar de las propuestas de la Comissione Bozzi, que no llegaron a materializarse en la realidad política, lo innegable es que con su constitución se puso de relieve los desajustes e imperfecciones que prevalecían- incluso hoy día permanecen- en la estructura del Estado italiano: a) la existencia de un alto grado de inestabilidad gubernamental y b) la absoluta marginación de los poderes públicos en la toma de decisiones.

Otras comisiones bicamerales continuaron a la Comissione Bozzi, siendo sus informes en un solo sentido que la antecesora. En el seno de estas comisiones legislativas señala Herrando (1998) se han discutido la viabilidad de adoptar un numeral de materias diferenciadas para cada una de las 
cámaras y otorgar a cada una de ellas representaciones diversas con el propósito de mejorar el devenir de las instituciones parlamentarias en el Estado italiano.

La búsqueda por adecuar a nuevos tiempos a las instituciones políticas y potenciar la eficacia y la estabilidad del Estado italiano, no ha sido estática puesto que han cobrado vigencia para su estudio y tratamiento en las diferentes comisiones bicamerales constituidas y sin que hasta ahora se haya finalizado este proceso de reestructuración de las instituciones. Hoy día, esta serie de aportacionespropuestas no han visto la luz y están en un impasse aguardando que las fuerzas políticas las retomen y los hagan suyas para de ese modo cerrar el círculo del diseño institucional emprendido a inicios de los 90 .

Es menester señalar que dada la fisionomía que ha creado la dinámica política el interés de las comisiones bicamerales por transformar el andamiaje institucional-constitucional, no será suficiente para que el Estado italiano transite a un nuevo diseño, mucho dependerá de la flexibilidad de los partidos ya que ellos son los que han constituido el núcleo de poder y han marginado de facto el papel que pudiera asumir las instituciones parlamentarias y de gobierno.

\section{CONCLUSIONES}

El formato bicameral se originó sobre dos hechos históricos- la monarquía constitucional y la Constitución americana- que marcaron un hito en los regímenes políticos actuales, puesto que ha servido como referente para establecer en el entramado legislativo una segunda cámara de representación territorial o de carácter político o, en su caso, una cámara revisora o una cámara investida de poder que impulsa un sistema de freno y contrapeso en el seno del Parlamento.

La configuración de la segunda cámara en los Estados contemporáneos está asociada fundamentalmente con el modelo federal, toda vez que es aquí donde adquiere relevancia y dinamismo al operar como un elemento necesario que consolida la estructura estatal y permite la articulación de los diferentes órdenes de Gobierno en la sede de la Federación. De igual modo, da vigencia al pacto federal en el entramado estatal al constituirse en una cámara territorial que confiere voz y representación a las colectividades territoriales en el proceso de toma de decisiones.

Contrario a este dictado es lo que experimenta Italia, pues aún cuando los constituyentes de 1947 configuraron un sistema electoral para que el Senado se estructure sobre una base regional (o territorial), tal mandato no ha propiciado para que este órgano sea en sentido lato un instrumento que ejerza la voz de las colectividades territorial en la dinámica nacional. Esta situación es así por dos razones: a) la legislación electoral solamente permite que la representación regional en el Senado alcance $1 / 4$ del total de escaños, lo cual hace que sea muy limitada; y b) el papel ejercido por los partidos políticos y, más concretamente, al sistema de partidos existente. Ambas situaciones, aunada a la existencia de una disciplina de partido han hecho que el Senado sea rehén de los partidos políticos y, en consecuencia, sean éstos los que monopolicen y decidan el cauce de la agenda legislativa.

El entramado surgido a la sombra del sistema de partidos en Italia, además de lo anterior, ha llevado que la formación de Gobierno se constituya sobre una democracia consociativa- palabras recogida de Arend Lijphart- en el cual sean cinco o siete partidos los que ejerzan y monopolicen el poder político, sin que el Parlamento o el Gobierno mismo, sean capaces de contravenir las decisiones emanadas de las directivas de los partidos. Esto es así puesto que han sido los propios institutos políticos constituidos en gobierno, los que también han dominado las dos cámaras. De ese modo, las cámaras al constituirse sobre mayorías parlamentarias similares, lo único que han 
hecho es ratificar las decisiones provenientes de los partidos $\mathrm{y}$, por consiguiente, se erija un Parlamento débil para hacer efectiva sus potestades constitucionales.

De 1960 a la fecha la vida política italiana no ha cambiado ni en su estructura y ni en su dinámica, toda vez que los partidos con mayorías parlamentarias han sido afines en las dos cámaras legislativas, lo que hace que ambas se complementen para legislar y aprobar leyes, imposibilitando con ello a que se ejerza en el régimen político un sistema de frenos y contrapesos.

\section{REFERENCIAS}

Aimo, P. 1977. Bicameralismo e regioni. Milano: Edizioni di Comunità.

Aja, Eliseo y Xavier Arbós. 1980. "El Senado, cámara posible de las autonomías". Revista de Estudios Políticos 17: 27-66.

Allegretti, U. 1989. Profilo di storia costituzionale italiana, individualismo e assolutismo nello Stato liberale. Bologna: Il Mulino.

Ghisalberti, C. 1978. Storia costituzionale d'Italia. Roma: Laterza.

Altamirano Santiago, Mijael. 2004. El senado en las democracias contemporáneas. México: Plaza y Valdés.

Aragón, M. 1990. "La función legislativa de los parlamentos actuales". En El parlamento y sus transformaciones actuales, editado por Angel Garrorena Morales. Madrid: Editorial Tecnos.

Biscaretti di Ruffáia, Paolo. 1987. Derecho constitucional. Madrid: Tecnos.

Burdeau, G. 1971. Traité de science politique. Tomo VI, Vol. II. Paris: Librairie Générale de Droit et Jurisprudence.

Cadoux, Charles. 1980. Droit constitutionnel et institutions politiques. Theorie Général des institutions politiques. Paris: s/e.

Chalvidan, Pierre-Henri. 1990. Les régimes politiques del' europe des douze. Paris : Ed. Eyrolles Universite Deuxieme.

Cheli, Enzo. 1978. Costituzione e sviluppo delle istituzioni in Italia. Bolonia: II Mulino.

Chimenti, Carlos. 1992. "Algunos rasgos del parlamentarismo italiano. Revista de Estudios Políticos 75: 7-46.

Chueca Rodríguez, Ricardo L. 1984. "El bicameralismo en la Constitución española". Revista Española de Derecho Constitucional 10: 63-90.

Justicia Vol. No. 35: pp. 83-103. Enero-Junio, 2019. DOI: 10.17081/just.24.35.3395 
Cillán García De I., María. 1990. "El sistema político y Senado, reflexiones en torno al bicameralismo". Anuario de la Facultad de Derecho. Cáceres: Universidad de Extremadura 8: 63-97.

Clinton, R. 1966. 1787: The Grand Convention. New York: Harcourt Brace.

Crisatulli, V. e L. Paladin. 1990. Commentario breve alla costituzione. Milano: Padua Editore. Milano.

Croisat, Maurice. 1994. El federalismo en las democracias contemporáneas. Barcelona: Hacer Editorial.

Delcamp, Alain. 1994. "France: L'expérience de décentralisation”. En Les collectivités décentralisées de I'Union Européenne dirigido por Alain Delcamp. Paris: La Documentation Française.

Dunn, Charles W. and W. Slann Martin. 1994. American Government, a comparative approach. New York: Harper Collins.

Duverger, M. 1961. Les règimes politiques. Paris: PUF.

Favoreu, Louis. 1995. "Bicamérisme et procédure législative". En Le bicamérisme. Paris: Economica.

Fernández Segado, Francisco. 1982. "La funcionalidad del Senado en cuanto a Cámara de Representación Territorial”. Revista Vasca de Administración Pública 13: 744.

Ferrando Badía, J. 1978. El Estado unitario, el federal y el Estado autonómico. Madrid: Editorial Tecnos.

Flauss, Jean-François. 1995. "La seconde chambre dans les états fédérés". Journée d'etudes. 17 mars. Paris: Presses Universitaires d'Aix-Marseille.

García Cotarelo, Ramón et al. (1993). Sistema político de la Unión Europea con inclusión de Estados Unidos y Japón. Madrid: Editorial Universitas.

García-Pelayo, Manuel. 1984. Derecho Constitucional Comparado. Madrid: Alianza Editorial.

Ghisalbert, C. 1974. Storia costituzionale d'Italia (1849-1948). Roma-Bari: Laterza.

González Encinar, José Juan. 1984. "Bicameralismo". En Diccionario del sistema político español dirigido por José Juan González Encinar y Dieter Nohlen. Madrid: Editorial Akal.

Justicia Vol. No. 35: pp. 83-103. Enero-Junio, 2019. DOI: 10.17081/just.24.35.3395 
Grangé, Jean. 1987. "Italia-Le Sénat de la Republique”. En Les secondes chambres du Parlement en Europe Occidentale dirigido por Mastias, J. et J. Grangé. París: Economica.

Guisalberti, Carlo. 1977. "Alle origini del Senato: modeli de esperienze". En II Senato nella storia, II Senato nell'etá moderna e contemporánea. Roma: Istituto poligrafico e zecca dello Stato, Libreria dello Stato.

Herrando García, Pedro J. 1998. "Proceso de reforma institucional de la Constitución Italiana: las conclusiones de la comissione bicamerale y el control parlamentario". En Parlamento y control del Gobierno coordinado por Francesc Pau i Vall. España: Editorial Aranzadi.

Hesse Joachim, Jesse and Vicent Wright (eds.). 1996. Federalizing Europe. The cost, benefits and preconditions of federal political system. Cambridge: Oxford University Press.

Jacques, R. et Jean-Marie Duby. 1997. “Le bicamérisme: bilan et perspective”. Revue du Droit Public et de la Science Politique en France et a l'Etranger 5: 1323-1350.

La Pérgola, Antonio. 1979. “Federalismo y regionalismo: Caso italiano". En Federalismo y regionalismo coordinado por Gumersindo Trujillo. Madrid: Centro de Estudios Políticos y Constitucionales.

Lauvaux, Philippe. 1987. Le parlamentarisme. Paris: PUF.

Lodici, Claudio. 1999. "Parliamentary y autonomy: the italian Senato". En Senates. Bicameralism in the contemporary world editado por Samuel D. Patterson \& Anthony Mughan. Columbus: Ohio State University.

Loewenstein, K. 1983. Teoría de la Constitución. Barcelona: Editorial Ariel.

Lucas Verdú, P. 1996. "Teoría del bicameralismo". En Tribunal sobre la reforma del Senado coordinado por Miguel Herrero Miñón. Madrid: s/e.

Luciani, Massimo. 1993. "La revisione costituzionale in Italia". En La révision de la Constitution dirigido por Louis Favoreu. París: Press Universitaires D’aix-Marseille, Economica.

Manzella, Andrea. 1991. II Parlamento. Bologna: II Mulino.

Martínez Sospedra, M. 1994. Las instituciones de gobierno institucional: sistema de gobierno y organizaciones constitucionales. Valencia: Fundación Universitarias CEU-San Pablo.

Mény, Yves. 1990. Goverment and politics in western Europe. Oxford: University Press.

Justicia Vol. No. 35: pp. 83-103. Enero-Junio, 2019. DOI: 10.17081/just.24.35.3395 
Montesquieu. 2003. Del espíritu de las leyes. De la colección Sepan Cuántos...". México: Editorial Porrúa.

Mouskheli, M. 1931. Teoría jurídica del estado federal. Madrid: Editorial M. Aguilar.

Negri, G. 1959. "Bicameralismo". en Enciclopedia di Diritto, Vol. V. Milano: Giuffrè.

Olivetti Rason, Nino. 1994. "Bicameralismo". En Diccionario de Política coordinado por Norbeto Bobbio et al. México: Siglo XXI.

Paladín, Livio. 1998. "Il método delle riforme: considerazioni sui lavori della Commissione Bicamerale". II Corriere Giuridico 1: 5-7.

italiano". Quaderni Costituzional 2: 219-242.

Pappalardo, A. 1995. "La nueva ley electoral en Italia". Revista de Estudios Políticos (Nuevo Época) 89: 61-80

Pasquino, Gianfranco. 1977. Corso di Scienza Politica. Bologna: II Mulino.

Pérez Ayala, A. 1997. "Transición política y reformas institucionales en Italia". Revista de Estudios Políticos (Nuevo Época) 95: 177-217.

Pérez Serrano, N. 1976. Tratado de Derecho Político. Madrid: Editorial Civitas.

Petschen, Santiago. 1993. La Europa de las regiones. Barcelona: Institut d'Estudis Autómics, Generalitat de Catalunya.

Presno Linera, M. Angel. 1994. "La reforma institucional italiana". Revista Española de Derecho Constitucional (14) 40: 133-159.

Rescigno, Francesca. 1995. Disfunzioni e prospettive di riforma del bicameralismo italiano. La Camera delle Regioni. Milano: Dott A. Giuffre Editore.

Rodríguez-Aguilera de Prat, Cesareo. 1988. "Los efectos del referéndum abrogativo en el sistema político italiano". Revista de Estudios Políticos 59: 107-154.

Roja, Argimio. 1991. La regionalización del Estado en la Europa comunitaria. Pontevedra: Fundación Galicia-Europa.

Rubio Llorente, F. y M. Daranas Peláez. 1997. Las constituciones de los estados de la Unión Europea. Barcelona: Ariel.

Sagües, Nestor P. 1992. "El Senado su fisonomía en el Estado federal y el Estado regional". En IV Congreso Iberoamericano de Derecho Constitucional. México: Universidad Nacional Autónoma de México.

Justicia Vol. No. 35: pp. 83-103. Enero-Junio, 2019. DOI: 10.17081/just.24.35.3395 
Sánchez Agesta, Luis. 1988. Curso de Derecho Constitucional Comparado. Madrid: Facultad de Derecho, Universidad Complutense de Madrid.

Sánchez González, Santiago y Pilar Mellado Prado. 1995. Sistemas políticos actuales. Madrid: Editorial Centro de Estudios Ramón Areces, S. A.

Spaldoni, G. 1993. Senato vecchio e nuovo, Dal Risorgimiento alla Repubblica. Firenze: Cassa Editrice Felice Le Monnier.

Trivelli, L. 1975. Le bicameralisme. Lausanne: Diffusion Payot.

Tsebelis, G. and J. Money. 1997. Bicameralism, Political Economy of Institutions and Decision. Cambridge: University Press.

Uriarte Torrealday, R. 1994. "El nuevo sistema electoral italiano y su inmediata incidencia en el sistema de partidos". Revista Vasca de Administración Pública 40 (1): 273-290.

Weber, Yves. 1972. "La crise du bicameralisme". Revue du Droit Public et de la Science Politique en France 5: 573-606.

Wheare, K. C. 1981. Legislature. México: LI Legislatura Cámara de Diputados. 